\title{
The Innovation of Educational Management Mode based on the Background of Big Data
}

\author{
Junnan $\mathrm{Yi}^{1}$ \\ Xijing University, Xi'an, 710123, China \\ E-mail: 516608324@qq.com \\ Shidan $\mathrm{He}^{2}$ \\ Xijing University, Xi'an, 710123, China \\ E-mail: 315705804@qq.com
}

\begin{abstract}
Big data brings the information storm transforming on our daily life and work mode ,the way of thinking big data era arrival is facing many opportunities and challenges to the ideological and political education in Colleges and universities. Based on the application of information technology to practice, we proposed three new concept of Ideological and political education innovation in Colleges and Universities: to quantify the integrated precise anticipation and personal philosophy, explore three new practice principles: visualization principles the principle of individualization and immediacy principle finally, based on the innovative practice of the University of Electronic Science and technology research center of large data, explore the shipment with big data technology to enhance the effectiveness of Ideological and political education new paths and models.
\end{abstract}

Keywords-Big Data; Innovative Education; Mode Innovation; Community Solar; Innovation Strategy

\section{PROJECT BACKGROUND}

Since 1990s, with the development of information and communication technologies and new business models are emerging to rely on business model innovation and create brilliant business model of Apple Amazon Haier and so on.[1] These innovations are mostly related to consumers and the world's most innovative digital technology and Internet related business model innovation on the central stage of global information technology and Internet related business model innovation, the basic era has come into every industry. [2-3] Wheel productivity growth and the arrival of the wave of consumer surplus.

Big data has a large amount of information and the characteristic of the high-end cutting-edge technology is changing the people's observation and understanding of the world's thinking and change path. [4]Finally, it will become the source of new knowledge and create new value. [5]

\section{OPPORTUNITIES AND CHALLENGES OF IDEOLOGICAL AND POLITICAL EDUCATION IN COLLEGES AND UNIVERSITIES}

Under the background of big data, people will make important decisions on Masumoto in data and analysis, rather than the experience and intuition of Ideological. Political education work is based on seizing this opportunity. Through the construction of integrated data platform, teachers and students together in the public data show a public network platform and the theme of the network questionnaire survey, and the work of Ideological and political education the quantitative and empirical problems of present era as big data described: data is like a magic diamond mine. [6] When it was discovered after the primary value, it can still continue to give ideological and political education faced with this opportunity to sum up these opportunities. Mainly in the following three aspects: According to the data analysis and analysis of the dynamic behavior of the students thinking and behavior data capture and analysis of students' thinking behavior dynamic value. Oriented and focus on social issues such as the value oriented and various compositions. The two is to achieve full sample of data analysis and the overall accuracy of data analysis. Is to make full use of empirical evidence. The three is to make full use of empirical evidence at the same time, teachers' teaching can increase the micro film and other ways of the video pictures, so as to realize the real time interaction between teachers and students, so as to enhance the effectiveness of Ideological and political education.

Personalized education idea: according to the data analysis conclusion and the visual of different education object, we should use the corresponding education process big data with different types of high quality and free sharing, open the new era of personalized education value, not only in data collection and analysis, more important is based on data analysis of specific students or individual students to provide personalized education. [7]In this regard, according to the data, the teachers have to carry out the education of students. On the other hand, the students can learn from their own knowledge, based on their own knowledge to develop their own learning and to enhance their motivation and effect. According to their own knowledge, the students can learn from each other.

Accurate judgments: the idea of dynamic data analysis and evaluation based on hot key word is the development trend of students' opinion. [8] Public opinion thought behavior can make accurate predictions in the judgment of the small data era, we should collect and analyze some samples to test the hypothesis, the investigators sample standard and the way of thinking of subjective bias problems such as interference. [9]Prone to distortion in the data era, samples for all not by the local error or individual difference interference, can accurately grasp the relevant 
factors of the objectivity of empirical relations. [10]So as to make accurate judgments on the relationship between the ideological and political education, which should be based on students' showing the learning life social interaction and other aspects of the data including the network consumer behavior of dormitory behavior the library learning behavior, based on the data related to), the overall comprehensive evaluation of the data on students' ideological behavior. Judge the recent student public opinion trends value oriented psychological state of mind early warning and so on, so as to provide scientific evidence for the public opinion or psychological intervention counter measures of Ideological Education.

\section{THREE NEW PRINCIPLES OF IDEOLOGICAL AND POLITICAL EDUCATION WORK IN COLLEGES AND UNIVERSITIES}

One is the visual principle: Based on the integration of different needs analysis, students thinking behavior can be different. Based on different big data computing method, the use of large data analysis techniques will minish the potential value of information, the students will have a comprehensive and accurate picture. And big data will help college ideological and political education workers full understand of students, grasp the students better in their studies and ideas so as to guide students, it also can help the functional departments to better manage the campus service.

Two is the personalized principle: According to the data analysis, different education methods and traditional ideological and political education theory course for all students would unify evaluation criteria and focus on the overall quality. Large data ideological and political education can be based on the characteristics of teachers or students. And based on the data of different grades, students will pay attention to social hot spots, according to the characteristics of different groups, and carry out targeted ideological and political education. As depicted in Figure 1.

Three is the principle of real-time: Based on the analysis of the data of students' thinking and behavior; the basic situation of the students' thinking behavior and the traditional ideological and political education; the basic situation and the traditional ideological and political education. The emphasis on the data are students.

The effect form to the students pay attention to the hot spots in the practice teaching is according to the latest data analysis conclusion, then timely adjust the teaching process. Teaching key or carrying out targeted classroom seminar social will practice investigation and solve the problems of the students' thinking and behavior.

\section{EXPLORATION AND NEW PATH OF EDUCATION IN THE ERA OF BIG DATA}

Based on the characteristics and advantages of big data, the research shows the process of College Ideological and political education. One of the focus of the research is to enhance the pertinence and effectiveness of Ideological and political education, the other is to develop and apply the new technology in education and Research Center, establishing different research projects.

The data is to understand their thinking and behavior characteristics. It wants to know real values of the tendency or mental health and other aspects. All of scientific analysis and research need the basic resources, need objective dynamic data as empirical analysis and conclusion of this science. So, University of Electronic Science and technology do this work from two aspects of Ideological and Political Education: one is to establish a data collection center study on the education data, constructing integrated information collection platform, School Counseling Center \& dorm center logistics service by the library office collaboration of different departments, establishing the system of the online data collection platform, in laws and regulations and individuals within the scope of authorization in open public space using network types of data collected. Two is the under-line of the teachers of Ideological and political education counselors organize thematic theme of network survey network learning and communication oriented data acquisition, the realization of students' thoughts and behavior of expression data. Through the two ways to realize the database platform of Ideological and political education information construction as depicted in Figure2.

The value of big data is to find practical problems and make judgments. How to use the database of Ideological and political education is a very challenging problem in practice innovation. University of Electronic Science and technology based on the idea of educating people with education data center and Ministry of education Marx Collaborative Learning Institute and other departments establish different project group according to different requirements, such as data acquisition data analysis team, data application team. Finally establish the platform construction departments of teacher or counselor project group according to the analysis of visualization Education Countermeasures of the ideological and political education chain: firstly, through the data platform, collecting information; secondly, functional departments ,Teachers and counselors to carry out online line activities, and then by the project group according to the algorithm presented problems in a visual way; finally, to develop a scientific and effective countermeasures. As depicted in Figure 3and 4..

According to a relatively stable mass data analysis methods and models, the electronic science and technology create an analysis of the characteristics of high school students, which are in accordance with the requirements of the stability of mass data and model. Electronic Science and technology create an analysis of the characteristics of high school students, want to create a model for the analysis of Ideological and political education, and to analyze the problem of students. The psychological consultation, such as the film and television play, carry out personalized customized targeted ideological and Political Education.

Compared to the traditional assessment of the quality of the classroom teaching quality and goals, the University of Electronic Science and Technology University has built up three teams: big data platform for building the top level design and the use of data mining. The three teams were constructed to build a big data era, ideological and political education of the main force. According to the data analysis of the appearance of the problem, then open the way of Internet related resources, such as domestic and overseas universities theme. All kinds of library resources are used 
to analysis students education exists the problems and hot spots, in classroom teaching, in a comprehensive way promotion by College Ideological and political education theory course.

\section{CONCLUSION}

Teaching model innovation is a systematic way of thinking and action orientation framework for teaching model innovation. And teaching model is the core of the model innovation research and practice is to solve the core issues of other big data, which has also been made in the field of other models innovation: teaching model innovation research and practice is the core issue of teaching model innovation research and practice.

Figures and Tables
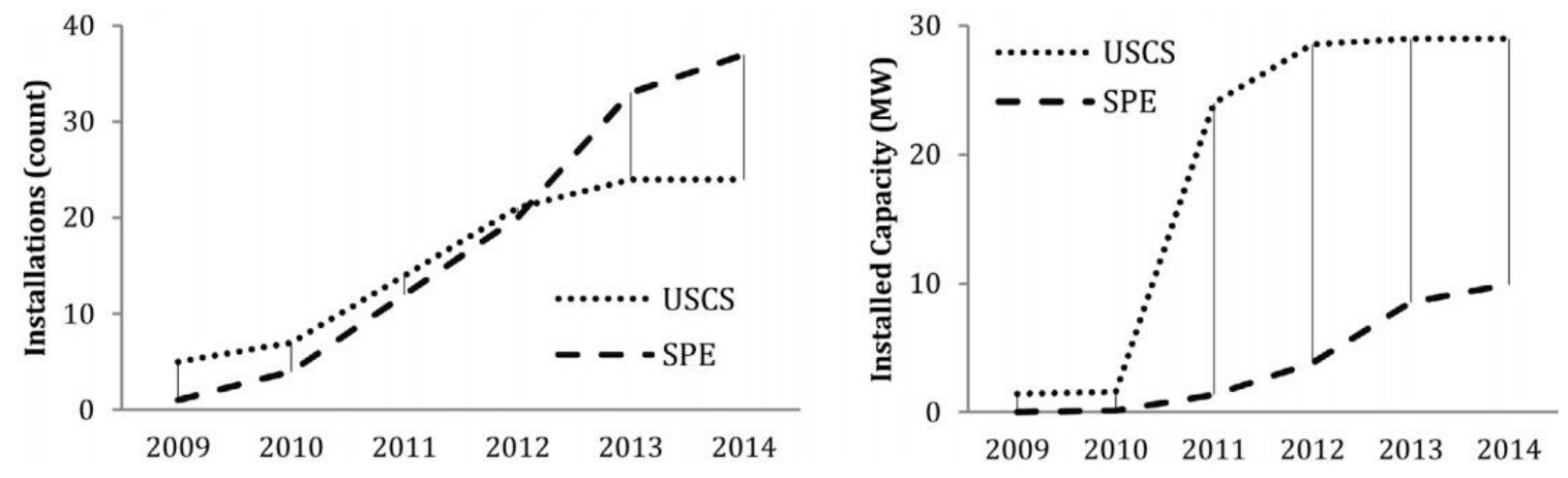

Figure 1.
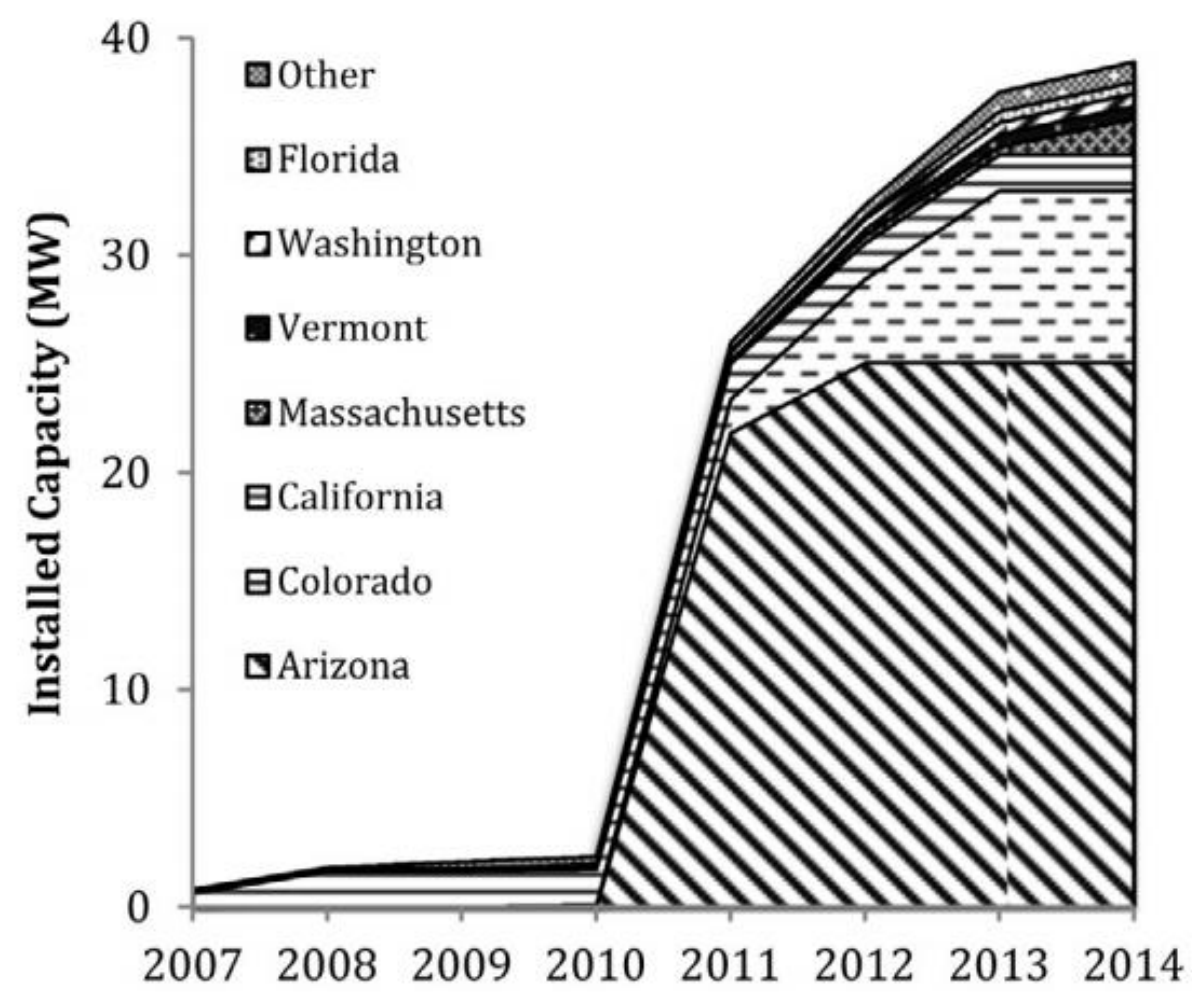

Figure 2 . 


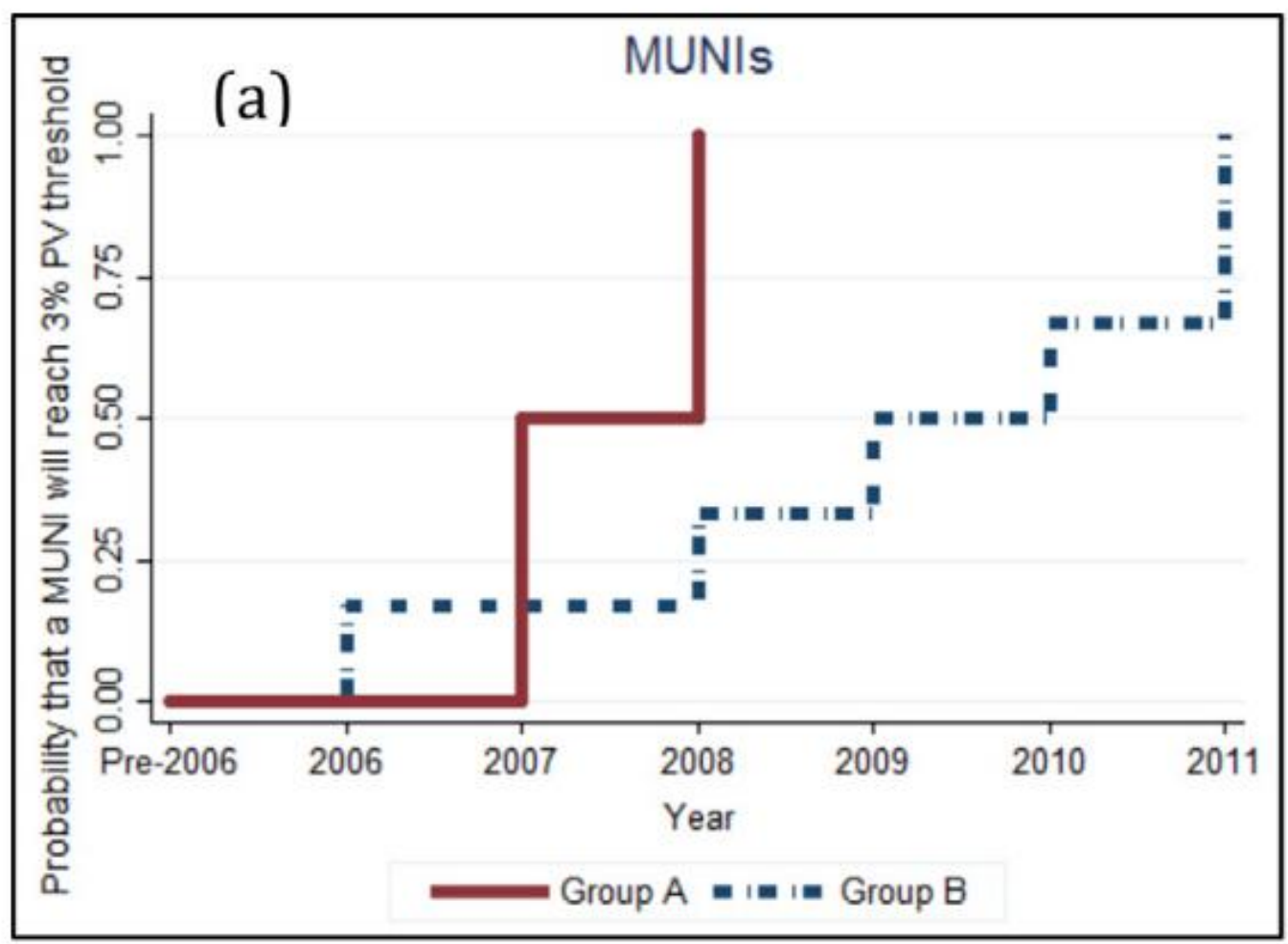

Figure 3.

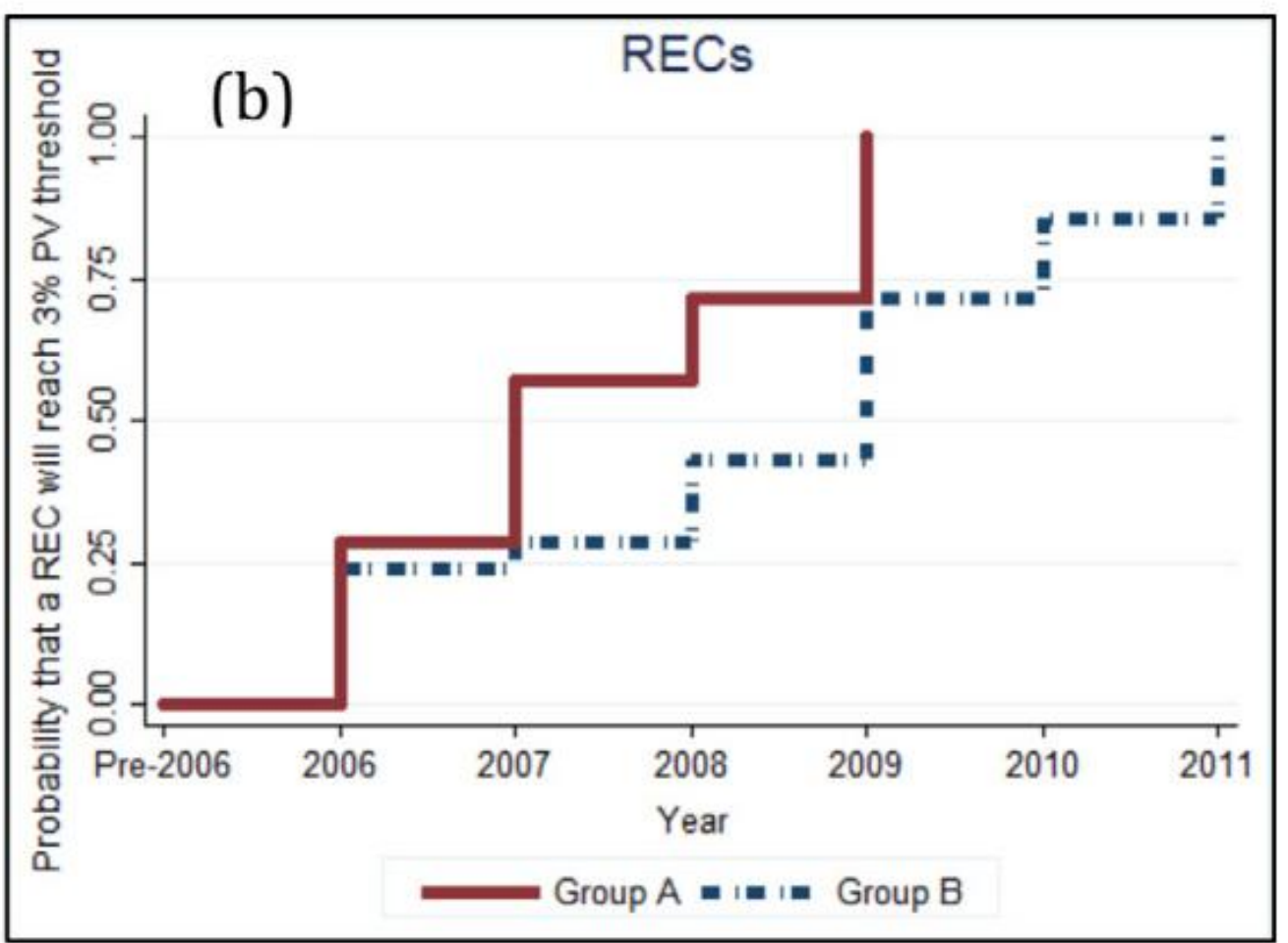

Figure 4. 


\section{REFERENCES}

[1] C. Cooper, J. Rose, M. Dworkin, Freeing the Grid: How Effective State Net Metering Laws Can Revolutionize US Energy Policy, Netw Energy Choices,2006.

[2] K.S. Cory, Renewable portfolio standards in the states: balancing goals andimplementation strategies, Natl. Renew. Energy Lab. (2007).

[3] J. Coughlin, J. Grove, L. Irvine, J. Jacobs, A Guide to Community Solar: Utility,Private and Non-Profit Project Development, 2011

[4] JCPUC, Introduction to the Net Energy Metering Cost Effectiveness Evaluation.Calif. Public Util. Comm. Energy Div, 2010.

[5] C. Davidson, D. Steinberg, R. Margolis, Exploring the market forthird-party-owned residential photovoltaic systems: insights from lease andpower-purchase agreement contract structures and costs in California,Environ. Res. Lett. 10 (2) (2015) 024006

[6] E. Drury, et al., The transformation of southern California's residentialphotovoltaics market through third-party ownership, Energy Policy 42 (2012)681-690.

[7] DSIRE, Texas: Renewable Generation Requirement. Database State Incent.Renewables Effic, 2014.

[8] EIA, Electric Power Sales, Revenue, and Energy Efficiency Form EIA-861Detailed Data Files. EIA (Energy Inf. Adm Washington, D.C. U.S. Energy Inf.Adm., 2012

[9] K. Gillingham, et al,, Deconstructing Solar Photovoltaic Pricing: The Role ofMarket Structure, Technology, and Policy, Ernest Orlando Lawrence BerkeleyNational Laboratory, Berkeley CA, US, 2014.

[10] D. Haugen, Minnesotta Plants Seeds for Community Solar Gardens, MidwestEnergy News, 2013, pp. 2013-2015 